\title{
Bilateral proficiency over time leads to reduced donor morbidity in living donor hepatectomy
}

\author{
Jan P. Lerut \\ Institut de Recherche Expérimentale et Clinique (IREC), Université catholique Louvain (UCL), Brussels, Belgium \\ Correspondence to: Prof. Jan P. Lerut, MD, PhD, FACS. Institut de Recherche Expérimentale et Clinique (IREC), Université catholique Louvain (UCL), \\ Avenue Hippocrates 10, 1200 Brussels, Belgium. Email: jan.lerut@uclouvain.be. \\ Provenance and Peer Review: This article was commissioned by the editorial office, Hepatobiliary Surgery and Nutrition. The article did not undergo \\ external peer review. \\ Comment on: Huang V, Chen CL, Lin YH, et al. Bilateral proficiency over time leads to reduced donor morbidity in living donor hepatectomy. \\ Hepatobiliary Surg Nutr 2019;8:459-69.
}

Submitted Aug 26, 2019. Accepted for publication Oct 24, 2019.

doi: 10.21037/hbsn.2019.10.30

View this article at: http://dx.doi.org/10.21037/hbsn.2019.10.30

In this issue of HSN, the very reputed Kaohsiung Liver Transplantation Center in Taiwan led by Prof. ChaoLong Chen reports about its extensive experience in the field of adult living donor liver transplantation (aLDLT). This paper gives a strong and very important message to the liver transplant community: excellent results can only be generated in LDLT when such program is developed carefully giving thereby attention to every possible detail during all steps of the donor and recipient procedures. Such attitude not only improves the quality of the surgical and medical care given to both donor and recipient but also allows, later on, an in-depth analysis of the obtained results...closing thereby the circle necessary to further raise the performance level of the team.

LDLT was introduced in clinical practice, first in 1989 by Strong and Tanaka in children, later on in 1993 by the Tanaka and Makuuchi teams in adults (1-3). It became rapidly clear that this formidable undertaking was very successful in small recipients but less so in larger (adult) recipients. In order to reduce the incidence of liver failure in the recipient, right-liver donation became, despite its documented higher morbidity, the preferred option $(85-90 \%)$ in LDLT $(4,5)$. The shift of the risk of the procedure from the recipient to the donor however hindered the widespread use of LDLT, especially in the Western world where LDLT represents only around 5\% of all LT activity (6).

The problems leading to reduced graft and patient survival rates in aLDLT were a source of intensive experimental and clinical research during the last two decades $(7,8)$. The unfavourable events encountered in donor and recipient became one by one unravelled. The Kyoto team paved the way by identifying the concepts of 'small for size graft and syndrome' and of 'graft hemodynamics" (9-11). Precise determination of graft and recipient anatomy and weight, modulation of in- and outflow of the allograft at implantation, precise monitoring of fluid balance by the anesthesiologist (surgical) intensivists and finally perfection of the peri-operative care slowly but surely closed the "outcome gap" between the small left-liver and the large right-liver LDLT procedures (12). Several teams managed to overcome the shortcomings caused by the use of small liver grafts and so proposed to turn back the clock. It was time to 'shift the risk from the donor to the recipient' fulfilling thereby the main ethical concern of LDLT, to guarantee maximal safety of the donor...who in fact is not a patient (!) but a healthy human carrying out the highest possible act of human solidarity (13-15). Left-liver retrieval, although considered (as confirmed in this paper) more difficult and time-consuming, enhances donor safety by leaving a larger residual liver volume. The key question which immediately comes up is if results of both graft types can be(come) equalized in donor and recipient? This fundamental question has been addressed in the Huang et al.'s paper (16) which excels by the way the "transplant center" and the "donor and recipient LDLT 
procedures" have been set up and by the way the analysis has been conducted. All analysed data are interpreted based on internationally accepted criteria such as the definition of post-hepatectomy liver failure and biliary leak following the International Study Group of Liver Surgery, gradation of complications following the Clavien-Dindo grading and the Comprehensive Complication Index and calculation of liver graft and remnant volumes. An original definition of post-donation ascites (precising even the calibre of the abdominal drain!) has also been introduced for the first time. Donor workup, graft selection, donor hepatectomy technique (including intra-operative cholangiography) and surgical intensive care management are all standardized and performed by the same 'in-house trained' team helmed by the same primary surgeon, CL Chen. This constellation allows to add to the "donor safety net" a last, non-negligible element, the flexibility to decide "in situ" about the final choice of the graft side to be taken.

The Kaohsiung team showed in this retrospective study, including 834 living donor hepatectomies performed during the period 2004-2014, that "bilateral proficiency" reduces donor morbidity and, more importantly, that outcome of left- and right-liver donation can be similar in both donor and recipient. The analysis focused on all donor complications in function of graft type used [221 left-liver (26.5\%) and 613 right-liver grafts] and era (2004 to 2010 and $\geq 2011$ ). During the second era the number of left-liver donations raised from 11 to $40 \%$. There was no donor mortality and the global donor morbidity was $17.6 \%$. Severe complications (Clavien-Dindo $\geq 3$ ) occurred in only $3.6 \%$ of donors. The right-liver donor population had significantly more and more severe complications, longer ICU and hospital stays, blood loss and ascites (none in left-liver donors). When comparing however results in relation to era, left-liver donor became not only protective but complication rates of right- and left-liver became similar as were 1 -year recipient outcomes with superior graft and patient survival rates of $95.9 \%$ in right-liver and 93.4\% in left-liver donation. Severe biliary complications were reduced by more than half in right-liver donation. The increased proportion of left-liver donation during the second era resulted in a better perioperative management of the patient('s fluid status) and so indirectly in a better outcome of right-liver donation.

The excellent, here reported, results confirm that experience is (probably) "the" most important factor determining the results of (a)LDLT. The worldwide implementation of (a)LDLT, which is badly needed to counteract the, continuously increasing, liver graft shortage, will only possible when experiences in this difficult field of medicine will be centralized in centers aiming at excellence. Excellence in liver surgery and liver transplantation can only be reached when giving continuous attention to details. LDLT centers and teams should keep in mind Winston Churchill's quote: "luck does not exist, what you call luck is notbing more than attention to details". The Kaohsiung team did this since more than a quarter of a century! (17).

\section{Acknowledgments}

Funding: None.

\section{Footnote}

Conflicts of Interest: The author has completed the ICMJE uniform disclosure form (available at https://hbsn. amegroups.com/article/view/10.21037/hbsn.2019.10.30/coif). The author has no conflicts of interest to declare.

Ethical Statement: The author is accountable for all aspects of the work in ensuring that questions related to the accuracy or integrity of any part of the work are appropriately investigated and resolved.

Open Access Statement: This is an Open Access article distributed in accordance with the Creative Commons Attribution-NonCommercial-NoDerivs 4.0 International License (CC BY-NC-ND 4.0), which permits the noncommercial replication and distribution of the article with the strict proviso that no changes or edits are made and the original work is properly cited (including links to both the formal publication through the relevant DOI and the license). See: https://creativecommons.org/licenses/by-nc$\mathrm{nd} / 4.0 /$.

\section{References}

1. Strong RW, Lynch SV, Ong TH, et al. Successful liver transplantation from a living donor to her son. $\mathrm{N}$ Engl J Med 1990;322:1505-7.

2. Ozawa K, Uemoto S, Tanaka K, et al. An appraisal of pediatric liver transplantation from living relatives. Initial clinical experiences in 20 pediatric liver transplantations from living relatives as donors. Ann Surg 1992;216:547-53.

3. Hashikura Y, Makuuchi M, Kawasaki S, et al. Successful living-related partial liver transplantation to an adult 
patient. Lancet 1994;343:1233-4.

4. Fan ST, Lo CM, Liu CL, et al. Safety and necessity of including the middle hepatic vein in the right lobe graft in adult-to-adult live donor liver transplantation. Ann Surg 2003;238:137-48.

5. Rössler F, Sapisochin G, Song G, et al. Defining benchmarks for major liver surgery: a multicentre analysis of 5202 living liver donors. Ann Surg 2016;264:492-500.

6. Halazun KJ, Przybyszewski EM, Griesemer AD, et al. Leaning to the left: increasing the donor pool by using the left lobe, outcomes of the largest single center north American experience of left lobe adult to- adult living donor liver transplantation. Ann Surg 2016;264:448-56.

7. Man K, Fan ST, Lo CM, et al. Graft injury in relation to graft size in right lobe live donor liver transplantation: a study of hepatic sinusoidal injury in correlation with portal hemodynamics and intragraft gene expression. Ann Surg 2003;237:256-64.

8. Kawasaki S, Makuuchi M, Ishizone S, et al. Liver regeneration in recipients and donors after transplantation. Lancet 1992;339:580-1.

9. Sakamoto S, Uemoto S, Uryuhara K, et al. Graft size assessment and analysis of donors for living donor liver transplantation using right lobe. Transplantation 2001;71:1407-13.

10. Ito T, Kiuchi T, Yamamoto H, et al. Changes in portal venous pressure in the early phase after living donor liver

Cite this article as: Lerut JP. Bilateral proficiency over time leads to reduced donor morbidity in living donor hepatectomy. HepatoBiliary Surg Nutr 2020;9(3):339-341. doi: 10.21037/ hbsn.2019.10.30 transplantation: pathogenesis and clinical implications. Transplantation 2003;75:1313-7.

11. Yamada T, Tanaka K, Uryuhara K, et al. Selective hemiportocaval shunt based on portal vein pressure for smallfor-size graft in adult living donor liver transplantation. Am J Transplant 2008;8:847-53.

12. Lee SG. A complete treatment of adult living donor liver transplantation: a review of surgical technique and current challenges to expand indication of patients. Am J Transplant 2015;15:17-38.

13. Ikegami T, Yoshizumi T, Sakata K, et al. Left Lobe Living Donor Liver Transplantation in Adults: What Is the Safety Limit? Liver Transpl 2016;22:1666-75.

14. Uemura T, Wada S, Kaido T, et al. How far can we lower graft-to-recipient weight ratio for living donor liver transplantation under modulation of portal venous pressure? Surgery 2016;159:1623-30.

15. Roll GR, Parekh JR, Parker WF, et al. Left hepatectomy versus right hepatectomy for living donor liver transplantation: shifting the risk from the donor to the recipient. Liver Transpl 2013;19:472-81.

16. Huang V, Chen CL, Lin YH, et al. Bilateral proficiency over time leads to reduced donor morbidity in living donor hepatectomy. Hepatobiliary Surg Nutr 2019;8:459-69.

17. Chen CL, Concejero AM, Cheng YF. More than a quarter of a century of liver transplantation in Kaohsiung Chang Gung Memorial Hospital. Clin Transpl 2011:213-21. 